\title{
Influence of Calcium Nitrite Based Accelerator, Steam Temperature and Pre-curing Time on the Compressive Strength of Mortar/Concrete
}

\author{
Abdul Ahmad Malikyar, Yuhji Sudoh, Nozomi Nakajima, and Shigeyuki Date
}

\begin{abstract}
The purpose of this study is to investigate the effect of Calcium Nitrite based accelerators concentrated $45 \%$ weight, pre-curing time and steam curing temperature on the strength gain of mortar, in the early and later age. Hence an experimental investigation was conducted to determine the optimum dosage of mentioned accelerators, and proper pre-curing time. Tests were performed on the specimens from various mixes considering to the $\mathrm{W} / \mathrm{C}$ ratio $30 \%$ and $40 \%$. Accelerator admixture was added in four series $(0,0.5,2$ and 4$) \%$, steam curing temperature was $65 \mathrm{C}^{\circ}$, and the pre-curing times were two patterns (pattern1 $=$ $0.5(\mathrm{hr})$ and the pattern $2=2.5(\mathrm{hr})$. Curing time was equal to both patterns that's $5(\mathrm{hr})$. The compressive strength test has been performed on the early age $(8, \mathrm{hr})$, and later age ( 7 and 28$)$ days, the obtained result compared with the strength of control specimens. To make the better fluidity, water reducing admixture was added by $0.5 \%$ weight of cement. From the result of the experiment, it has been observed that high strength for early and later ages obtained for the specimens that made with $4 \%$ accelerator admixture and exposed to the longer pre-curing cycle.
\end{abstract}

Index Terms-Calcium nitrite, accelerator admixture, steam curing temperature, mortar, pre-curing cycle, compressive strength.

\section{INTRODUCTION}

Increasing the usages of precast Concrete element coupled with demand for high productivity in the precast concrete industries, so higher early strength gain of concrete the most important issue that has a significant influence for early removal of mould in the precast concrete industry. Faster and safer removal of shuttering in precast concrete Plants increase the productivity. This rising enables the economic advantage. In order to develop the strength gain of concrete at early age with good performance in precast industry. Different factors has been applied to bring sufficient changes on the strength gain of concrete, such as material properties [1], concrete composition [2], Concrete replacement [3], compaction factor and cure cycle [4]- [8]. Several admixtures and high curing temperature have been used to get a concrete with sufficient strength at a very early age [9]-[15]. Calcium chloride is one of the Admixture, which is used for this purpose as the set and

Manuscript received, November 3, 2016; revised May 12, 2017.

Abdul Ahmad Malikyar, Nozomi Nakajima, and Shigeyuki Date are with Tokai University/Civil Engineering Department, 4-1-1 Kitakaname, Hiratsuka-shi, Kanagawa 259-1292, Japan (e-mail: ahmad_ahmad2793@yahoo.com, hayabusa_ripobitann_0613@yahoo.co.jp, sadt@tokai-u.jp).

Yuhji Sudoh is with Nissan Chemical Industries, Ltd. /Basic Chemical Department, 3-7-1, Kanda-Nishiki-Cho, Chiyoda-Ku, Tokyo 101-0054, Japan (e-mail: sudouyuuji@ nissanchem.co.jp). hardening accelerator. The most cost-effective accelerator for all Portland cement concrete is calcium chloride. Though there has been disagreement over the use of calcium chloride in reinforced concrete in assessment of the possibility of corrosion. In many civil Engineering codes, its use is being prevented for concrete embedded metal [9]-[11]. Effect of temperature on the different properties of concrete is substantial. From the past research it has been observed, that, usages of high steam curing temperature is more effective on the early strength of concrete, but on the other hand, it has an adverse effect on the later strength of concrete [12]- [14]. The study has been observed, using Calcium Nitrate alone, on concrete mixes with normal tricalcuim silicate content $(8.33 \%)$, the calcium Nitrate effected significantly the evolution in the early age compressive strength, they increased by $50 \%$ at 1 and 3 days compared with reference. It has been observed, that calcium Nitrate is very active as a corrosion inhibitor for metal imbedded in concrete [15].

\section{A. Research Significance}

This study is performed to investigate the effect of calcium Nitrite based accelerator concentrated 45\% weight, pre-curing cycle, and the effect of steam curing temperature on the compressive strength gain at the early age ( 8 , hours), and later ages ( 7 , and 28 ,days). The study aim was to prepare a reference for obtaining the higher early compressive strength, for the precast concrete element, while Calcium Nitrite has been used as accelerator admixture, on the concrete mixes, and steam curing temperature has been used as curing methods, without harmful effect on the later age compressive strength. Based on the experimental results, higher early and later age compressive strength was observed for the specimens made with adding $4 \%$ Calcium Nitrite accelerator and exposed to the longer pre-curing cycle 150 minutes. While the steam curing temperature was $65 \mathrm{C}^{\circ}$, and the type of applied cement was Ordinary Portland cement, the water-cement ratios were $30 \%$ and $40 \%$. We are requesting that you follow these guidelines as closely as possible.

\section{EXPERIMENTAL STUDY}

\section{A. Materials}

The general formula of the CNA that applied in the present research is illustrated in Table I. Ordinary Portland cement type 1 is used for this study. The physical properties and chemical analysis are shown in Table II and Table III, respectively. The fine aggregate used for this study is river 
sand. Abbreviations and acronyms of material which has been used for this study are illustrated in Table IV.

\begin{tabular}{lcc} 
TABLE I: PROPERTIES OF (CALCIUM NITRITE BASED ACCELERATOR) \\
\hline Description & $\begin{array}{c}\text { Total } \\
\text { Concentration }\end{array}$ & Specific Gravity \\
\hline Amount & $45.1 \%$ & 1.43 \\
\hline
\end{tabular}

TABLE III: PHYSICAL PROPERTIES FOR CEMENT TYPE1

\begin{tabular}{cccc}
\hline \hline Description & $\begin{array}{c}\text { Ignition } \\
\text { loss }(\%)\end{array}$ & $\begin{array}{c}\text { Specific Surface } \\
\left(\mathrm{cm}^{2} / \mathrm{g}\right)\end{array}$ & $\begin{array}{c}\text { Density } \\
\left(\mathrm{gr} / \mathrm{cm}^{3}\right)\end{array}$ \\
\hline Amount & 2.26 & 3340 & 3.16 \\
\hline \hline
\end{tabular}

TABLE III: CHEMICAL COMPOSITION FOR CEMENT TYPE1

\begin{tabular}{llllllll}
\hline \hline $\mathrm{MgO}$ & $\mathrm{SO}_{3}$ & $\mathrm{CL}-1$ & $\mathrm{Na}_{2} \mathrm{Oeq}$ & $\mathrm{C}_{3} \mathrm{~S}$ & $\mathrm{C}_{2} \mathrm{~S}$ & $\begin{array}{l}\mathrm{C}_{3} \\
\mathrm{~A}\end{array}$ & $\begin{array}{l}\mathrm{C}_{4} \mathrm{~A} \\
\mathrm{~F}\end{array}$ \\
\hline $\begin{array}{l}1.41 \\
\%\end{array}$ & $2.1 \%$ & $\begin{array}{l}0.015 \\
\%\end{array}$ & $0.5 \%$ & $56 \%$ & $18 \%$ & $\begin{array}{l}9 \\
\%\end{array}$ & $9 \%$ \\
\hline \hline
\end{tabular}

TABLE IV: ABBREVIATIONS AND ACRONYMS OF MATERIAL WHICH HAS BEEN USED FOR THIS STUDY

\begin{tabular}{clcl}
\hline \hline Materials & Acronym & Properties & \\
\hline Cement & $\mathrm{N}$ & $\begin{array}{c}\text { Ordinary Portland } \\
\text { Density3.16 } \mathrm{g} / \mathrm{cm}^{3}\end{array}$ & Cement, \\
\hline $\begin{array}{c}\text { Fine } \\
\text { Aggregate }\end{array}$ & $\mathrm{S}$ & $\begin{array}{c}\text { River Sand from } \quad \text { Kanagawa } \\
\text { density } 2.69 \mathrm{~g} / \mathrm{cm}^{3} . \\
\text { surface-dry condition) }\end{array}$ & (Saturated \\
\hline Admixture & $\mathrm{CN}$ & $\begin{array}{c}\text { Accelerator }(\mathrm{Calcium} \text { Nitrite } \\
\text { based concentrate 45\% weight) }\end{array}$ \\
\cline { 2 - 5 } & $\mathrm{SP}$ & $\begin{array}{c}\text { High-performance AE water } \\
\text { reducing agent delay Type (UE) }\end{array}$ \\
\hline \hline
\end{tabular}

\section{B. Curing Method}

Curing temperature, curing time, ambient temperature, and early crashing time are all clarified in Fig. 1.

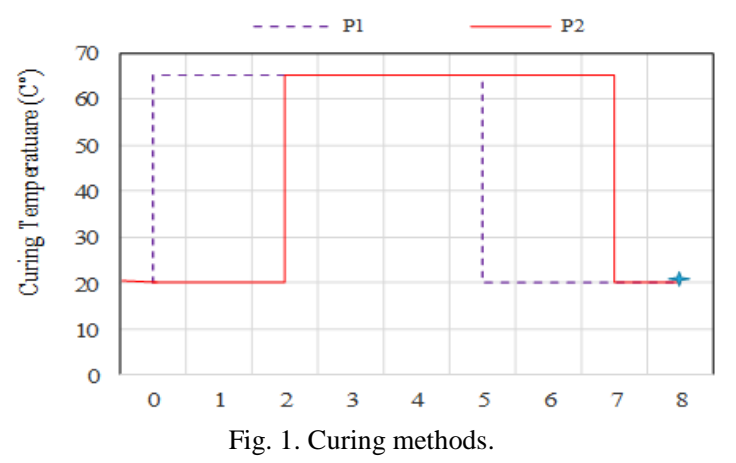

\section{EXPERIMENTAL TACTIC}

\section{A. Compressive Strength Test}

For compressive strength test, specimens were casted from both mixing series of water binder ratio $30 \%$ and $40 \%$. In this study investigation was performed for two patterns of procuring cycle, pattern1, pre-curing cycle was 30 minutes, and for pattern 2 pre-curing cycle was 150 minutes, CNA ( $0 \%$, $0.5 \%, 2 \%$ and $4 \%$ by weight of cement) were added. Specimens casted and exposed to steam curing for 5 hours, at the end of steam curing for 5hours in steam curing chamber, all the specimens demolded, and three specimens were tested at each different age (8 hours, 7 days and 28 days), for compressive strength test in order to evaluate the interaction of accelerator with type of mixes, water binder ratio and methods of curing according to the Fig. 1 in the compressive strength development of the mortar / concrete. Control specimens were casted from each mixing series, and cured in the ambient temperature $\left(20 \mathrm{C}^{\circ}\right)$, after testing for compressive strength at the ages of 8hours, 7days and 28 days. For each step, three specimens were crushed.

\section{RESULT AND DISCUSSION}

\section{A. Influence of Accelerator Admixture on the Compressive Strength at Different Ages for Series 1, Water Binder Ratio $30 \%$}

Compressive strength of specimens assessed by compression test. The high rate of early compressive strength gain is very important in the precast concrete industry to be enable for faster and safer demolding to increase the production. Hence, compressive strength was recorded at the age 8 hours, 7 days and 28 days. The values are shown in Table V and Fig. 2 for pattern 1. And also for pattern 2, it is illustrated in Table VI and Fig. 3. Percentage gain in the strength of mixture added a varied dosage of accelerator, in comparison to the strength of control specimens was calculated. From the results in Fig. 2, and Fig. 3, it has been obtained that the accelerator admixture has a considerable effect on the strength gain at the early and later ages, as well as it makes ensure about the later ages compressive strength. It showed that by increasing the accelerator admixture dosage, the compressive strength increased, it could be seen for both patterns (P1 and $\mathrm{P} 2$ ) of concrete mixes in order to the $(\mathrm{W} / \mathrm{C}=30 \%)$.

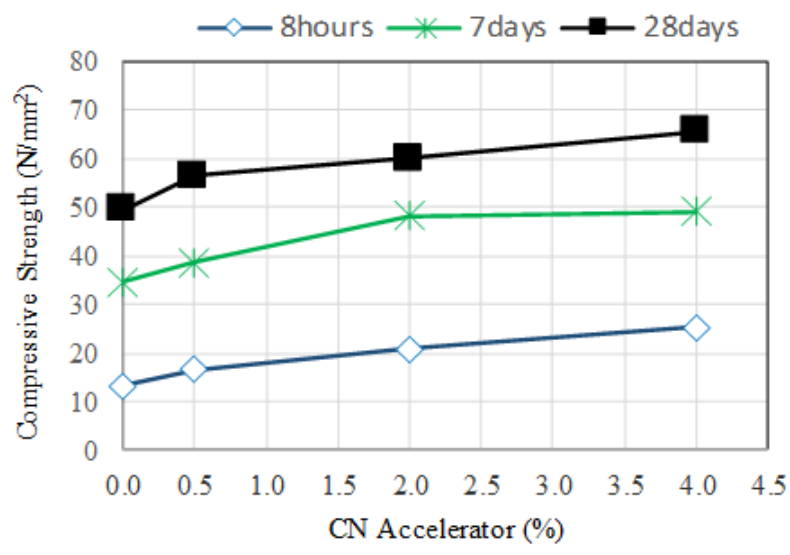

Fig. 2. Variation in compressive strength based accelerator P1.

TABLE V: COMPRESSIVE STRENGTH IN N/MM² FOR (W/C=30\%) PATTERN 1

\begin{tabular}{l|c|c|c}
\hline \hline \multirow{2}{*}{ CNA } & \multicolumn{3}{|c}{ Avg. Compressive Strength $\left(\mathrm{N} / \mathrm{mm}^{2}\right)$} \\
\cline { 2 - 4 } & 8 hours & 7 days & $\begin{array}{c}28 \\
\text { days }\end{array}$ \\
\hline $0 \% \mathrm{CN}$ & 13.33 & 34.67 & 49.53 \\
$0.5 \% \mathrm{CN}$ & 16.57 & 38.7 & 56.5
\end{tabular}




\begin{tabular}{cccc}
$2 \% \mathrm{CN}$ & 20.9 & 48.2 & 59.9 \\
\multirow{2}{*}{$4 \% \mathrm{CN}$} & 25.33 & 49.2 & 65.63 \\
\multirow{2}{*}{ Reference } & 0.24 & 65.2 & 76.53 \\
\hline \multirow{4}{*}{ CNA } & \multicolumn{4}{r}{ Avg. Compressive Strength $\left(\mathrm{N} / \mathrm{mm}^{2}\right)$} \\
\hline \multirow{4}{*}{$0 \% \mathrm{CN}$} & 8 hours & 7 days & 28 days \\
\hline \multirow{2}{*}{$0.5 \% \mathrm{CN}$} & 15.17 & 39.13 & 50.33 \\
$2 \% \mathrm{CN}$ & 18.37 & 40.93 & 58 \\
$4 \% \mathrm{CN}$ & 25.07 & 50.53 & 64.33 \\
Reference & 27.2 & 62.8 & 74.3 \\
\cline { 2 - 4 } & 0.24 & 65.2 & 76.53 \\
\hline
\end{tabular}

\section{B. Influence of Accelerator Admixture on the Compressive Strength at Different Ages for Series Two Water Binder Ratio $40 \%$}

According to the recorded results in Table VII and Table VIII, it has been obtained that the percentage of the strength gain in order to the influence of accelerator dosage at the early age for the specimens casted from mixes by (W/C ratio 40\%) is increased slightly, it is probably due to the high water contents present in the mortar mixes, and non-completion of the hydration procedure for whole cement particles at the early age, but for the later age at 7 and 28 days, the percentage of strength gain for all the specimens bases of accelerator dosage are significantly observable. From the result it has been obtained that by increasing the dosage of calcium nitrite based accelerator the compressive strength is increased. It is shown that, when the water contents tend upward the influence of Accelerator admixture is more perceptible on the later ages.

Moreover, the result shown that the early compressive strength of specimens which exposed to the short pre-curing time, is slightly higher than the early compressive strength of those specimens which exposed to the long pre-curing time. It is due to the effect of pre-curing time on the strength gain when water binder is higher.

TABLE VII: VARIATION IN COMPRESSIVE STRENGTH BASED ACCELERATOR DOSAGE AND CONTROL SPECIMEN (W/C $=40 \%$ ) P1

\begin{tabular}{l|l|c|c}
\hline \hline \multirow{2}{*}{ CNA } & \multicolumn{3}{|c}{ Avg. Compressive Strength $\left(\mathrm{N} / \mathrm{mm}^{2}\right)$} \\
\cline { 2 - 4 } & 8 hours & 7 days & $\begin{array}{c}28 \\
\text { days }\end{array}$ \\
\hline $0 \% \mathrm{CN}$ & 7.73 & 23.67 & 30 \\
$0.5 \% \mathrm{CN}$ & 8.07 & 23.63 & 33.37 \\
$2 \% \mathrm{CN}$ & 9.04 & 24.83 & 36.37 \\
$4 \% \mathrm{CN}$ & 11 & 49.2 & 45.37 \\
Reference & 0.29 & 40.8 & 45.8 \\
\hline \hline
\end{tabular}

TABLE VIII: VARIATION IN COMPRESSIVE STRENGTH BASED ACCELERATOR DOSAGE AND CONTROL SPECIMEN (w/C $=40 \%)$ P2

\begin{tabular}{l|l|c|c}
\hline \hline \multirow{2}{*}{ CNA } & \multicolumn{3}{|c}{ Avg. Compressive Strength $\left(\mathrm{N} / \mathrm{mm}^{2}\right)$} \\
\cline { 2 - 4 } & 8 hours & 7 days & $\begin{array}{c}28 \\
\text { days }\end{array}$ \\
\hline $0 \% \mathrm{CN}$ & 7.9 & 21 & 27.5
\end{tabular}

\begin{tabular}{llll}
$0.5 \% \mathrm{CN}$ & 8 & 21.63 & 28.37 \\
$2 \% \mathrm{CN}$ & 8.53 & 22.50 & 35 \\
$4 \% \mathrm{CN}$ & 9.65 & 26.7 & 42.33 \\
Reference & 0.29 & 40.8 & 45.8 \\
\hline
\end{tabular}

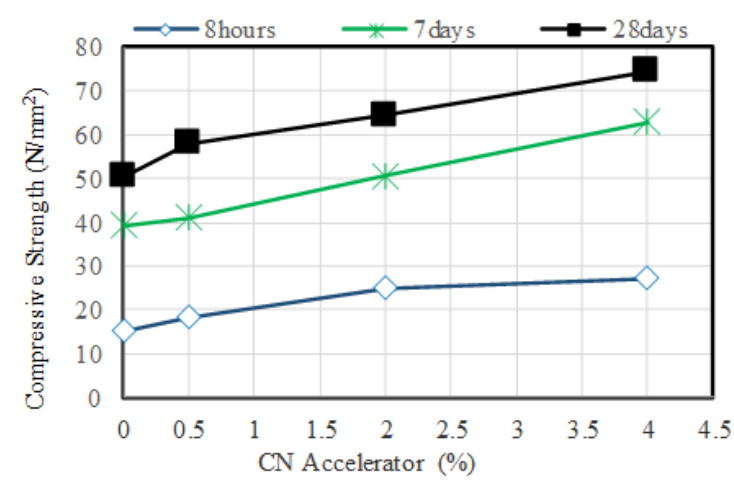

Fig. 3. Variation in compressive strength based Accelerator P2.

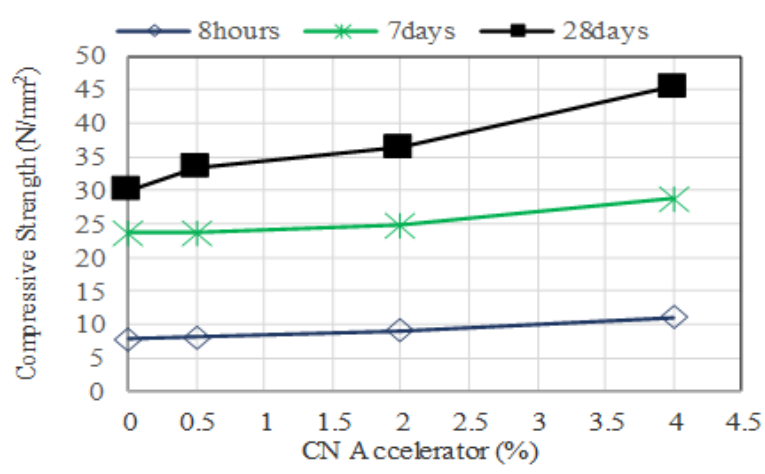

Fig. 4. Variation in compressive strength based Accelerator P1.

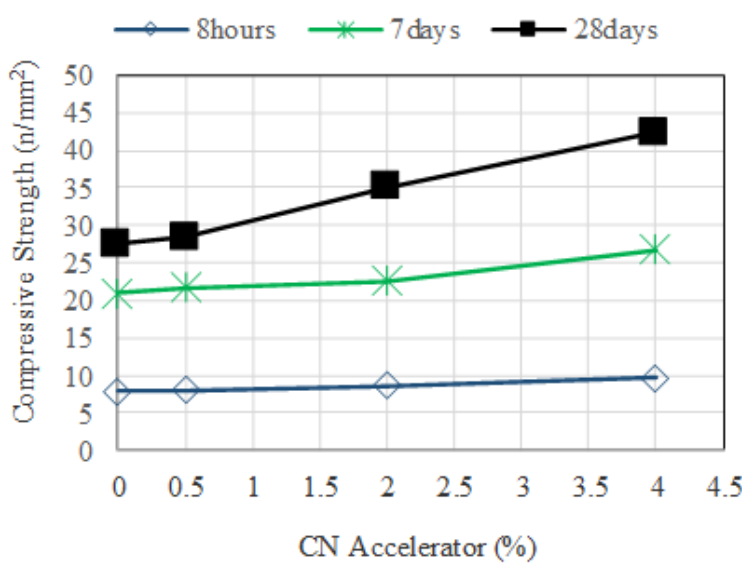

Fig. 5. Variation in compressive strength based Accelerator P1.

\section{Comparing the Strength Gained at Different Ages and the Optimum Dosages of Admixture for both Water Cement Contain}

Variation in the compressive strength at different ages of specimens due to the effect of a varied dosage of Calcium Nitrite based accelerator admixture, and influence of steam curing temperature $\left(65 \mathrm{C}^{\circ}\right)$ is illustrated in Fig. 6, Fig. 7, Fig. 8 and Fig. 9. The experimental results indicate that steam curing temperature increases the early age strength gain, but it has an adverse effect on the later age, strength. Consider to the result for specimens' made with $0 \%$ accelerator admixture, and exposed to the steam temperature $\left(65 \mathrm{C}^{\circ}\right)$ and compressive strength of control specimens that cured in the air at ambient 
temperature $\left(20 \mathrm{C}^{\circ}\right)$. From the result, it has been obtained that Calcium Nitrite based accelerator admixture has a significant influence on the compressive strength gain at different ages (early and later). So by applying the optimum dosage of accelerator admixture and exposed specimens in steam curing, the adverse effect of high curing temperature on the later age strength can be compensated. According to the result, the later age compressive strength of those specimens made with $4 \%$ accelerator approximately equal to the compressive strength of control specimens. For both series of the water binder ratio $30 \%$, and $40 \%$.

Fig. 10, illustrated comparison, between compressive strength of specimens made with $0 \%$, and $4 \%$ accelerator admixture to the compressive strength of control specimens. The result has been shown that the initial compressive strength of specimens made with $0 \%$ accelerator and subjected to the steam curing temperature $\left(65 \mathrm{C}^{\circ}\right)$ are higher than the initial strength of control specimens $98.2 \%$, and 98.4\% for pattern 1 and 2 respectively. But adversely, the later strength of control specimens is higher than the later strength of specimens made with $0 \%$ accelerator and exposed to the steam curing temperature, $54.5 \%$ and $52.1 \%$ for pattern 1 and 2 respectively. The evaluation of compressive strength between specimens made with $4 \%$ accelerator and control specimens shown that the initial strength of specimens having $4 \%$ accelerator is higher $(99.1 \%)$, than the initial strength of control specimens for both patterns. But in the later age, the compressive strength of specimens having $4 \%$ accelerator was slightly lower $16.6 \%$ and $3 \%$ for pattern 1 and 2 respectively.

Fig. 11 comparison of the initial and later age strength between specimens added $0 \%$ and $4 \%$ accelerator and exposed in steam curing temperature to the strength of control specimens in order to the mortar with water binder ratio $40 \%$. The result showed the initial strength of specimens made with $0 \%$ and $4 \%$ accelerator are higher than the strength of control specimens (97\%) for both patterns. But in later age 28 (day), the strength of control specimens was considerably higher than the strength of specimens having $0 \%$ accelerator and exposed to high temperature, and it is approximately equal to the strength of specimens having $4 \%$ accelerator and exposed to the steam temperature in both patterns.

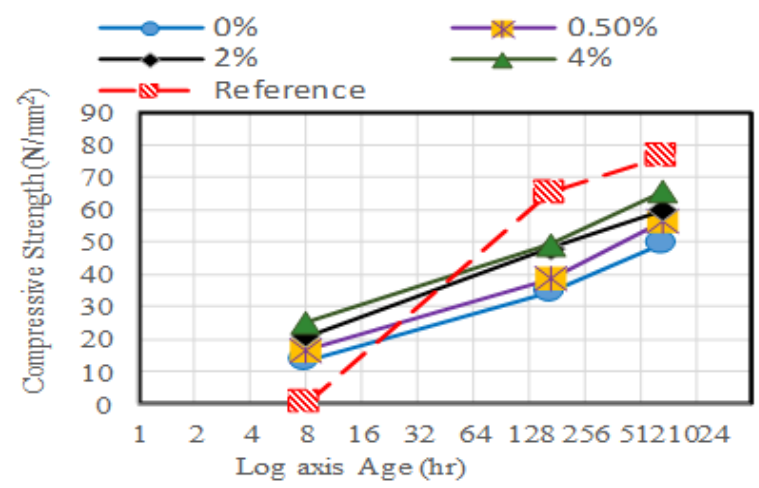

Fig. 6. Variation in compressive Strength based accelerator dosage and steam curing temperature for $\mathrm{w} / \mathrm{c}=30 \%$, pattern 1

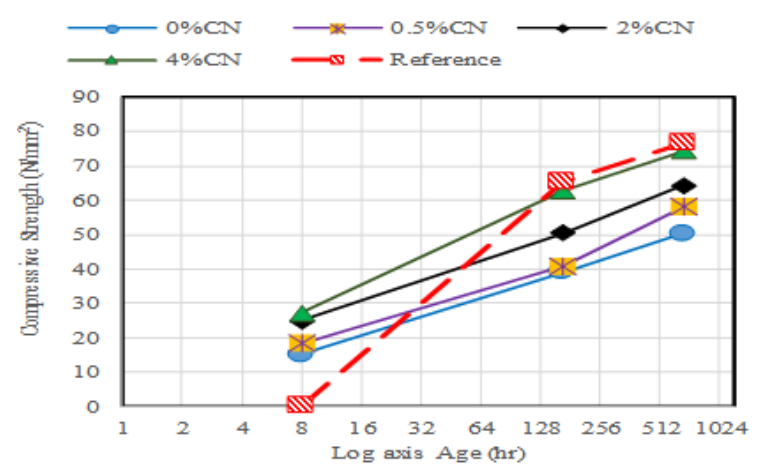

Fig. 7. Variation in compressive strength based accelerator dosage and steam curing temperature for $\mathrm{w} / \mathrm{c}=30 \%$, pattern 2 .

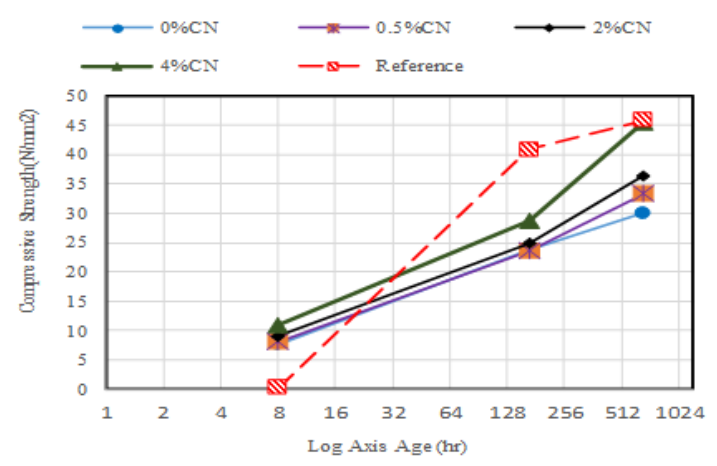

Fig. 8. Variation in compressive strength based accelerator dosage and steam curing temperature for $\mathrm{w} / \mathrm{c}=40 \%$, pattern 1 .
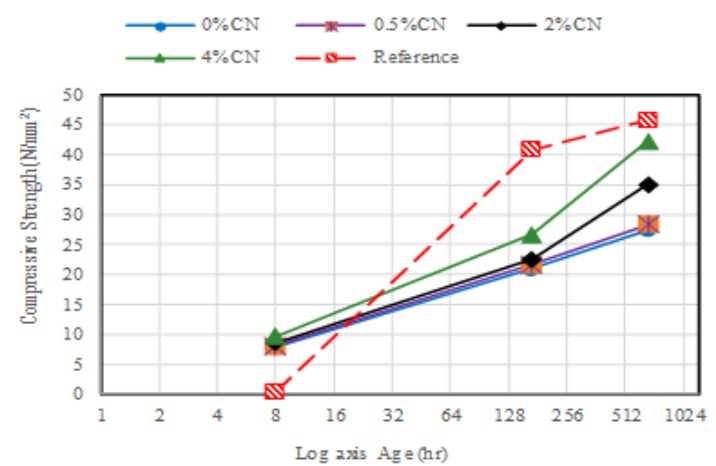

Fig. 9. Variation in compressive strength based accelerator dosage and steam curing temperature for $\mathrm{w} / \mathrm{c}=40 \%$, pattern 2 .

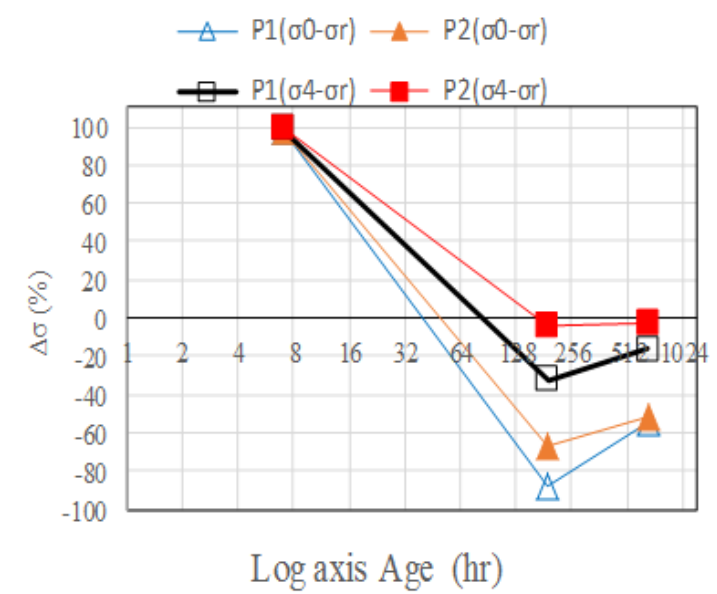

Fig. 10. Variation of percentage in the Compressive strength $\mathrm{P}(1$, $2), w / c=30 \%$. 


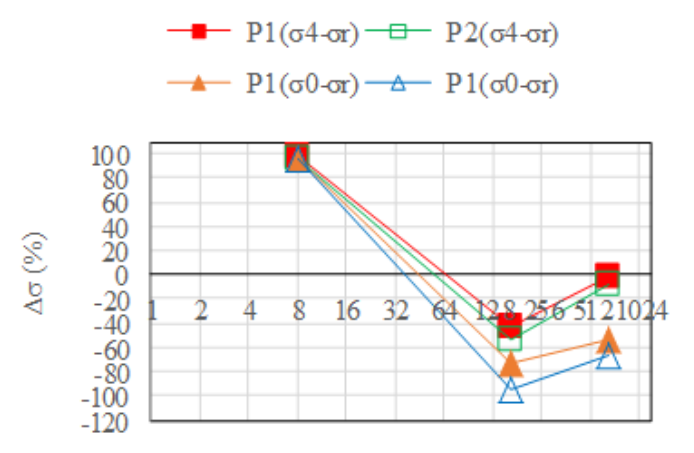

Log axis Age (hr)

Fig. 11. Variation of percentage in the compressive strength $\mathrm{P}(1,2)$, $\mathrm{w} / \mathrm{c}=40 \%$.

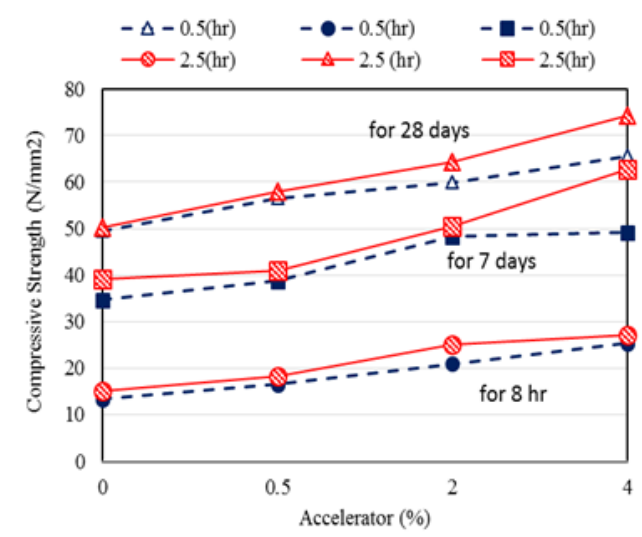

Fig. 12. Variation in compressive strength based pre-curing time, $\mathrm{w} / \mathrm{c}=30 \%$.

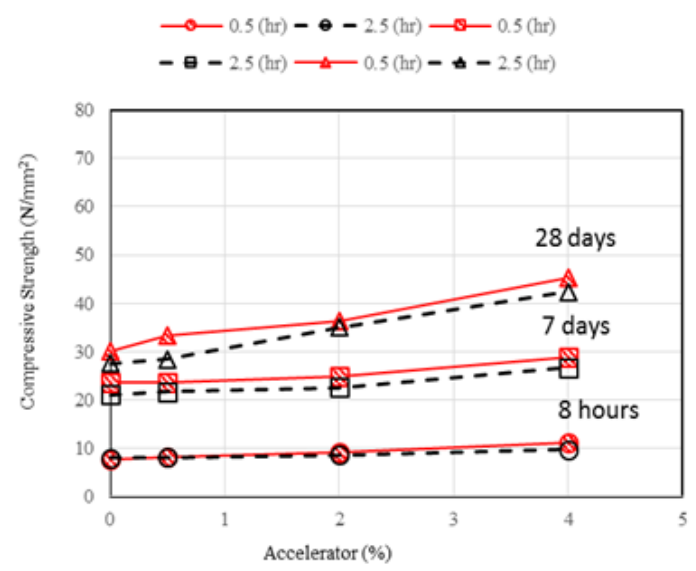

Fig. 13. Variation in compressive strength based pre-curing time, $\mathrm{w} / \mathrm{c}=40 \%$.

\section{Influence of Pre curing Time on the Compressive Strength Gain}

In the most precast concrete plant to increase the production of the precast concrete element and sufficiently used of the mould, after casting the concrete in mould immediately or after a short time the fresh concrete exposure in the steam curing with high temperature. In this study the effect of short pre-curing (30minutes) and long pre-curing (150 minutes) in the compressive strength gain were investigated.

According to the result in Fig. 12 for (w/c=30\%), it has obtained that the compressive strength of specimens exposed to the long pre-curing time are slightly higher than the compressive strength of those specimens travelled in short pre-curing time. But in Fig. 13 for $(\mathrm{w} / \mathrm{c}=40 \%)$, it is determined that the compressive strength of specimens which covered in short pre-curing time are slightly higher than those specimens which subjected to the long pre-curing time.

\section{CONCLUSION}

The test has been carried out on the mortar specimens to investigate the effect of Calcium Nitrite based accelerator, steam curing temperature and the effect of pre-curing time on the compressive strength at early and later age. The main results can be draws as follows:

By using the Calcium Nitrite based accelerator admixture to increase the strength gain at early and later age can compensate the adverse effect of high steam temperature at the later age strength.

Calcium Nitrite based accelerator concentrated 45\% weight, acted as a hardening accelerator at different ages. Among three varied dosage of accelerator admixture it has been obtained that the $4 \%$ calcium nitrite accelerator admixture is the optimum dosage.

Pre-curing is one of the important factor affecting to the compressive strength at different ages, and it depends on the water binder ratio for the specimens with low water content the longer pre-curing time has a better influence on the strength gain at different ages, but for high water binder ratio the shorter pre-curing time acted to improve the later age strength gain than the longer pre-curing.

There is high demands for using precast concrete due to several advantages such as, economic issue, environmental factors, duration of the construction project and quality control, are coupled to speed up the production rate in the precast concrete industry. Thus, to increase the rate of production of precast concrete, utilization of accelerators admixture has a significant role. Based on this study, it is suggested: That to investigate the influence of Calcium Nitrite as accelerator admixture on the microstructure of concrete, in future.

\section{REFERENCES}

[1] H. A. Mohammad, Effect of Flyash and Silica Fume on Compressive Strength, Ain Shams Engineering Journal June, 2011.

[2] R. Mačiulaitis, "The effect of concrete composition and aggregates properties on performance of concrete," Journal of Civil Engineering and Management, vol. 15, no. 3, pp. 317-324.

[3] E. B. Ogunbode and I. O. Hassan, "Effect of addition of calcium nitrate on selected properties of concrete," Leonardo Electronic Journal of practices and Technologies Issue, 19, July - December 2011.

[4] H. B. Baradan, Research, Effect of Curing Temperature and Relative Humidity on the strength Development of Portland Cement Mortar, Scientific Research and Essays, 18 June 2011.

[5] T. K. Erdem, L. Turanli, and T. Y. Erdogan, "Setting time: An important criterion to determine the length of the delay, period before steam curing of concrete," Cement and Concrete Research, vol. 33, 2003, pp. 741-745.

[6] A. A. Ramezanianpour, M. H. Khazali, and P. Vosoughi, "Effect of steam curing cycles on strength and durability of SCC: A case study in precast concrete," Construction and Building Materials, vol. 49, 2013, pp. $807-813$.

[7] A. H. Hameed, "The effect of curing condition on compressive strength in high strength concrete," Diyala Journal Of Engineering Sciences, vol. 02 , pp. 35-48, June 2009. 
[8] H. A Toutanji and Z. Bayasi, "Effect of curing procedures on properties of silica fume concrete," Cement and Concrete Research, vol. 29, 1999, pp. 497-501.

[9] J. A. Naqash, "Effect of accelerating admixture on properties of concrete," IOSR Journal of Engineering March 2014. Society of Civil Engineers, Appendix document, pp. I-270 to I-271.

[10] Roar Myrdal, Accelerator admixture for concrete, COIN-Concrete innovation Centre, 2007-12-05.

[11] P. Rapp, "Research, effect of calcium chloride on Portland cement and concrete," Journal of the National Bureau of Standards, vol. 14, April 1935.

[12] M. F. Ba, "Effects of steam curing on strength and porous structure of concrete with low, Water/binder ratio," 2010.

[13] S. Tqrkela and V. Alabasb, "The effect of excessive steam curing on Portland composite," Cement Concrete, Cement and Concrete Research, vol. 35, 2005, pp. 405-411.

[14] S. Erdog`du and S. Kurbetci, "Optimum heat treatment cycle for cements of different," Type and Composition. Cement and Concrete Research, vol. 28, no. 11, pp. 1595-1604, 1998.

[15] M. C. Zouaoui and N. Chikh, "Research, effect of calcium nitrate and triisoproponolamine on the setting and strength evolution Portland cement part," Materials and Structures, vol. 41, no. 1, pp. 31-36, January 2008.

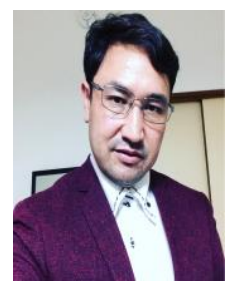

Abdul Ahmad Malikyar was born in Afghanistan He graduated from Kabul Polytechnic University, Civil and industrial Construction Department in 2006. He is a student of Graduate School of Tokai University, Department of Civil Engineering. Kanagawa, Japan. His research title is optimization of production of precast concrete. He has experience for 9 years in Concrete construction work, and pre cast concrete production. He is a member of JSCE.

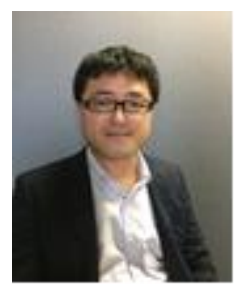

Yuhji Sudoh was born in Tokyo, Japan. He received his doctor degree of engineering in civil engineering from Kitami Institute of Technology in 2007. He major field of study: concrete engineering, maintenance engineering. $\mathrm{He}$ is working for Nissan Chemical's Head Quarters, as Manager of Concrete chemicals section, Tokyo, Japan. Current and Previous research interests are Development of Chemical admixture and Repairing materials for Concrete. He is member of JCI, JSCE, AIJ, and SMSJ.

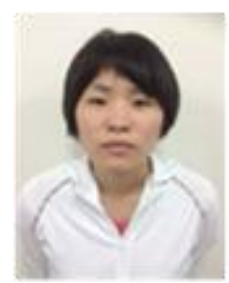

Nozomi Nakajima was born in Tokyo Japan. She received her bachelor degree of civil engineering course in Tokai University, Hiratsuka city, Japan, March 2016. She is a candidate for master course of civil engineering at Tokai University. Her research interests are about engineering of precast concrete. She is a member of JSCE and JCI conference.

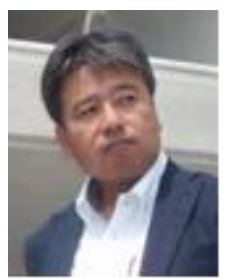

Shigeyuki Date was born in Fukuoka Pref. Japan. He graduated from Nagasaki University in 1987, a doctor of engineering, Gumma University in 2005, Gumma Japan. He major field of study: concrete engineering, maintenance engineering. He is working for Tokai Univ. as Professor of Dept. of Civil Engineering, 4-1-1 Kitakaname Hiratsuka Kanagawa Japan. Current and Previous research interests are material design, durability of concrete structure, Concrete production, and pre-cast Concrete. Dr. Date is a member of JCI, JSCE, AIJ, and SMSJ. 